\title{
Palliative Chemotherapy in Advanced Non-Small-Cell Lung Cancer: Goals and Reality
}

\author{
T. Beinert $^{a} \quad$ H.-G. Mergenthaler ${ }^{b} \quad$ O. Sezer ${ }^{a} \quad$ K. Possinger ${ }^{a}$ \\ ${ }^{a}$ Medizinische Klinik und Poliklinik m. S. Hämatologie und Onkologie, Universitätsklinikum Charité, Berlin \\ ${ }^{\mathrm{b}}$ Klinik für Onkologie, Zentrum für Innere Medizin, Katharinenhospital, Stuttgart
}

Lung cancer is the most common malignancy among men, and the incidence in women continues to rise [1]. For 1998, the American Cancer Society reported that $13 \%$ of patients suffering from lung cancer will be cured due to improvements in surgical resection techniques in early-stage non-small-cell lung cancer (NSCLC). However, the majority of patients still cannot be cured. About 70\% of patients with NSCLC, accounting for $80 \%$ of all lung cancer patients, have locally advanced tumours or even metastases at the time of diagnosis. Furthermore, the majority of patients undergoing curative therapy do relapse, resulting in at least $85 \%$ of NSCLC patients who need palliative therapy [2].

Until a few years ago, therapy of NSCLC was synonymous with best supportive care, and chemotherapy was not administered except in clinical studies. However, several metaanalyses were published demonstrating small survival improvement in patients with advanced NSCLC who had undergone chemotherapy [3, 4]. Furthermore, quality of life was significantly enhanced in those patients, demonstrating a clear benefit of chemotherapy in NSCLC $[3,5]$.

Recently, the superiority of chemotherapy compared to best supportive care has been demonstrated in several studies, and advanced NSCLC is now considered to be generally treatable with chemotherapy not only for reasons of improved survival, but also for improved quality of life. This change in the goals of tumour therapy is due to qualitative end points of palliative tumour therapy (which can be paraphrased by the slogan 'quality versus quantity of life').

Since then, a number of new drugs such as vinorelbine [6], gemcitabine [7], paclitaxel [8] and docetaxel [9] have been introduced, characterised by increased antitumour activity and only mild side-effects. Subsequently, a remarkable number of (phase II) studies were conducted to test combinations of these drugs $[10,11]$, as well as combinations of them with wellestablished tumour drugs such as platinum $[12,13]$.

Although these efforts have not yet succeeded in creating a gold standard for chemotherapy of advanced NSCLC [5,14], results so far have been quite encouraging. Results reported at the 1996 ASCO Meeting already showed that chemotherapy treatment of patients with nonresectable NSCLC not only doubled survival, but led to a significant improvement in their quality of life [15].
Therefore, patients with advanced NSCLC should now be treated with chemotherapy. Even if a new therapy standard is still lacking, many promising new regimens have already proven to support local as well as systemic tumour control, and these regimens should be administered to these patients.

However, the reality is different. It is estimated that at least one-third of patients with advanced NSCLC are treated with 'best supportive care', one-third with conventional, older and cheaper chemotherapy regimens, and at best only one-third of NSCLC patients do profit from the results of the therapy trials of recent years [16]. In this respect, it is important to emphasise that there is a direct link between the kind of therapy applied, the type of hospital, and the level of economic restrictions. To some extent, new treatment regimens seem to be reserved for the small minority of NSCLC patients treated in university hospitals. Thus the realisation of new therapy concepts designed for all patients fails due to financial restrictions - an unsolvable contradiction between goals and reality in palliation of NSCLC.

With this in mind, a fundamental dilemma arises in the discussion about the best therapy regimen for advanced NSCLC. The ongoing studies completely ignore the actual economic situation of the therapy units, which are under increased budgetary pressure. There is a growing danger that a possible benefit in palliation due to advanced therapeutic regimens will be too expensive and thereby remain out of reach for most patients. One suspects that many NSCLC patients are categorised as 'not worthy being treated with chemotherapy' at the point of diagnosis and therefore will not be seen by an oncologist. Thus the number of NSCLC patients who should be treated with chemotherapy may be even greater than estimated today, thereby further increasing the discrepancy between desirable and actually administered therapy.

This situation is discouraging since the majority of NSCLC patients do not benefit from the results of the therapy studies of the last years, nor might they profit from the therapy studies of the future. Besides economic restrictions, this unfortunate situation is also due to a lack of knowledge of the physicians who are not familiar with the therapeutic options in advanced NSCLC. It is necessary to point out an important fault: a general lack of tumour documentation. Nowadays, at least 20 tools

\begin{tabular}{ll}
\hline KARER & (1) 1999 S. Karger GmbH, Freiburg \\
& Fax (0761) 4520714 \\
www.karger.com & Accessible online at: \\
http://BioMedNet.com/karger
\end{tabular}


are used for tumour documentation in Germany. However, up to now, neither exists a consensus of normative quality standards in tumour documentation nor are there data collected in a joint data pool.

Qualitative end points of palliation in NSCLC are needed, yet have not been identified. Since measurements of qualitative goals have not yet been evaluated, these objectives will not be able to serve as quality control for a long time. However, quality control of therapy should be much less of a tool for controlling the physician who administers the therapy, but rather a tool for demonstrating the need for certain therapeutic standards which benefit the patient. Consequently, the documentation of meeting quality standards may be the key in overcoming some economic restrictions. To put it more bluntly, the lack of tumour documentation may be part of the lack of quality control in palliation, and the lack of quality control in palliation reflects unfavourably on the deteriorating economic situation.

How can this situation be overcome? On the one hand, an improved information system, i.e. tumour documentation about the outcome of the ongoing trials, is mandatory. On the other hand, this data base should include all cancer patients treated with drugs, regardless of the type of hospital or outpatient unit in which the therapy is administered. The data base could amplify the exchange of experience, thereby building the basis for quality control. This could be the beginning of an area of cost-benefit analyses or cost-effectiveness analyses in palliation, needed to identify and quantitate the patient's benefit in times of economic restrictions - e.g., as already shown for advanced pancreatic cancer [17].

Further insights are needed in to the mechanisms of palliative therapy of NSCLC. Besides clinical trials and the testing of new drug combinations in NSCLC therapy as well as multimodal therapy regimens, more light must be shed upon the interacting mechanisms, e.g., induction of apoptosis, antineogenesis, cytolysis, synergism of chemotherapy and radiation [14], etc. Further basic research is needed, especially in tumour palliation, since the majority of NSCLC patients still cannot be cured, but should nevertheless benefit from the advances in cancer therapy.

\section{References}

1 Mannino DM, Ford E, Giovino GA, Thun M: Lung cancer deaths in the United States from 1979 to 1992 An analysis using multiple-cause mortality data. Int J Epidemiol 1998;27:159-166.

2 Schmidt W, Altmannsberger M, Steiner S: The natural course in nonresectable non-small-cell lung cancer. A critical analysis. Onkologie 1997;20:132-136.

3 Souquet PJ, Chauvin F, Boissel JP, Cellerino R, Cormier Y, Ganz PA, Kaasa S, Pater JL, Quoix E, Rapp E, et al: Polychemotherapy in advanced non small cell lung cancer: A meta-analysis. Lancet 1993; 342:19-21.

4 Marino P, Pampallona S, Preatoni A, Cantoni A, Invernizzi F: Chemotherapy vs supportive care in advanced non-small-cell lung cancer: Results of a metaanalysis of the literature. Chest 1994;106:861-865.

5 Manegold C, Drings P: Zur Rolle der Chemotherapie beim nichtkleinzelligen Bronchialkarzinom (NSCLC) im Tumorstadium III. Onkologie 1994;17:294-302. 6 Crawford J, O'Rourke M, Schiller JH, et al: Randomized trial of vinorelbine compared with fluorouracil plus leucovorin in patients with stage IV non-smallcell lung cancer. J Clin Oncol 1996;14:2774-2784.
7 Manegold C, Drings P, Von Pawel J, et al: A randomized study of gemcitabine monotherapy versus Etoposide/Cisplatin in the treatment of locally advanced or metastatic non-small-cell lung cancer. Semin Oncol 1997;24(suppl 8):813-817.

8 Rowinsky EK, Wright M, Monsarrat B, Donehower RC: Clinical pharmacology and metabolism of Taxol (paclitaxel): Update 1993. Ann Oncol 1994;5 (suppl 6):S7-16.

9 Fossella FV, Lee JS, Shin DM, et al: Phase II study of docetaxel for advanced or metastatic platinumrefractory non-small-cell lung cancer. J Clin Oncol 1995;13:645-651.

10 Georgoulias V, Kourousis C, Kakolyris S, Androulakis N, Dimopoulos MA, Papadakis E, Kotsakis T, Vardakis N, Kalbakis K, Merambeliotakis N Hatzidaki D: Second-line treatment of advanced non-small cell lung cancer with paclitaxel and gemcitabine: A preliminary report on an active regimen. Semin Oncol 1997;24(suppl 12):61-66.

11 Miller VA: Docetaxel (Taxotere) and vinorelbine in the treatment of advanced non-small-cell lung cancer: Preliminary results of a phase I/II trial. Semin Oncol 1997;24 (suppl 14): S15-17.
12 Colleoni M, Boni L, Vicario G, et al: A dose-escalating study of carboplatin combined with vinorelbine in non-small-cell lung cancer. Oncology 1996;53: 364-368.

13 Bunn PA: Chemotherapy with paclitaxel and platinum compounds: Current status and future directions. Vol 1: Non-small cell lung cancer - Introduction. Semin Oncol 1995;22(suppl 9):1.

14 Schraube P, Latz D, Manegold C, Bischoff H, Krempien P, Preßler K, Wannenmacher M, Drings $\mathrm{P}$ : Concurrent radiochemotherapy with ifosfamide in unresectable stage III non-small-cell lung cancer. Onkologie 1998;21:57-62.

15 Bunn PA: New Drug Combinations in the Treatment of Advanced Non-Small Cell (NSCLC) and Small Cell (SCLC) Lung Cancer. ASCO Educational Book 1996, pp 196-207.

16 P.M.I.S, Lenka Kellermann: TherapieMonitor ${ }^{\odot}$ NSCLC IIIab/IV, 1997, Freiburg.

17 Mergenthaler HG, Lüftner D, Possinger K: Chemotherapy and chemo-radiotherapy of advanced pancreatic carcinoma. Onkologie 1996;19:308-312. 